\title{
Milling Processes and Hydrogen Storage Properties of Mg-Graphene Composites
}

\author{
Young Jun KWAK ${ }^{1}$, Eunho CHOI ${ }^{2}$, Myoung Youp SONG ${ }^{1, *}$ \\ ${ }^{1}$ Division of Advanced Materials Engineering, Hydrogen \& Fuel Cell Research Center, Engineering Research Institute, \\ Chonbuk National University, 567 Baekje-daero Deokjin-gu Jeonju, 54896, Republic of Korea \\ ${ }_{2}^{2}$ Department of Materials Engineering, Graduate School, Chonbuk National University, 567 Baekje-daero Deokjin-gu \\ Jeonju, 54896, Republic of Korea
}

cross $^{\text {ref }}$ http://dx.doi.org/10.5755/j01.ms.25.3.20567

Received 13 April 2018; accepted 16 July 2018

\begin{abstract}
Graphene was chosen as an additive to improve the hydrogen uptake and release properties of magnesium (Mg). Five weight percent of graphene was added to $\mathrm{Mg}$ or pre-milled $\mathrm{Mg}$ by milling in hydrogen (reactive milling). The milling processes and hydrogen uptake and release properties of the graphene-added $\mathrm{Mg}$ were investigated. Adding graphene to $\mathrm{Mg}$ and then milling the mixture of $\mathrm{Mg}$ and graphene in hydrogen for $6 \mathrm{~h}$ [named M5G $(6 \mathrm{~h})$ ] had little effects on the improvement of hydrogen uptake and release properties of $\mathrm{Mg}$. Pre-milling of $\mathrm{Mg}$ (for $24 \mathrm{~h}$ ) and then adding $5 \mathrm{wt} \%$ of graphene by milling in hydrogen (for $30 \mathrm{~min}$ ) (named M5G) significantly increased the hydrogen uptake and release rates and the quantities of hydrogen absorbed and released for $60 \mathrm{~min}$ of $\mathrm{Mg}$. The activation of M5G was completed after cycle number, $\mathrm{CN}$, of two $(\mathrm{CN}=2)$. M5G had a high effective hydrogen-storage capacity of $6.21 \mathrm{wt} . \%$ at $623 \mathrm{~K}$ in $12 \mathrm{bar}_{2}$ at $\mathrm{CN}=3$. M5G released $0.25 \mathrm{wt}$.\% hydrogen for $2.5 \mathrm{~min}$ and $5.28 \mathrm{wt}$.\% hydrogen for $60 \mathrm{~min}_{2}$ in $1.0 \mathrm{bar}_{2}$ at $623 \mathrm{~K}$ at $\mathrm{CN}=3$. Pre-milling of $\mathrm{Mg}$ and then adding graphene by milling in hydrogen and hydrogen uptake-release cycling are believed to create defects, produce cracks and clean surfaces, and decrease particle sizes.

Keywords: hydrogen storage materials, milling in hydrogen, hydrogen uptake and release rates, microstructure, graphene-added $\mathrm{Mg}$ alloy.
\end{abstract}

\section{INTRODUCTION}

Magnesium (Mg) is known to have excellent hydrogen-storage properties, except that it has low hydrogen uptake and release rates. To increase the hydrogen uptake and release rates of $\mathrm{Mg}$, transition metals like $\mathrm{Pd}[1], \mathrm{Cu}[2], \mathrm{Co}, \mathrm{Ni}$ or $\mathrm{Fe}[3,4]$, and $\mathrm{Ti}$ [5], rareearth metals such as La and $\mathrm{Y}[6]$, graphite [7,8], or intermetallic compounds such as $\mathrm{Mg}_{2} \mathrm{Ni}, \mathrm{LaNi}_{5}$, and FeTi [9-11] have been added to $\mathrm{Mg}$.

Of the studies in which carbon materials have been doped, Huot et al. [7] synthesized a metallic hydride rapidly by milling $\mathrm{Mg}$ with graphite at a high temperature under hydrogen pressure. They were able to form hydride by milling a mixture of $\mathrm{Mg}+5$ at $\% \mathrm{~V}+$ graphite at $573 \mathrm{~K}$ under 4 bar $\mathrm{H}_{2}$ for $1 \mathrm{~h}$. Popilevsky et al. [8] synthesized pelletized porous composites of $\mathrm{Mg}$ admixed with $2 \mathrm{wt} . \%$ of either multiwall carbon nanotubes or graphite. They reported that the best combination of hydrogen desorption kinetics, thermal conductivity, and mechanical stability was obtained for the pellets synthesized from the mixture of $\mathrm{Mg}$ with $2 \mathrm{wt} \%$ of carbon nanotubes processed by $4 \mathrm{~h}$ of co-milling [8]. Imamura et al. [12] obtained nanocomposites by mechanically milling $\mathrm{Mg}$, graphite, and organic additive (benzene, cyclohexene or cyclohexane). In the obtained nanocomposites, many dangling carbon bonds were formed in the graphite due to the decomposition of the graphite structure, which was caused by mechanical milling. The hydrogen absorbed in these

\footnotetext{
* Corresponding author. Tel.: +82-63-270-2379; fax: +82-63-270-2386

E-mail address: songmy@jbnu.ac.kr (M.Y. Song)
}

nanocomposites existed as a $\mathrm{C}-\mathrm{H}$ bond type in graphite and as hydride type in $\mathrm{Mg}$.

Graphite has a high thermal conductivity compared with most metals except gold, silver, copper, and aluminium. When graphite is added to $\mathrm{Mg}$, it can thus help the sample have higher hydrogen uptake and release rates by dispersing heat rapidly. The average specific gravity of graphite is $1.6-2.0$, which is smaller than the specific gravity of aluminium, and the specific surface area of graphite is large.

In the present work, graphene was chosen as an additive to improve the hydrogen uptake and release properties of $\mathrm{Mg}$. Five weight percent of graphene was added to $\mathrm{Mg}$ or pre-milled $\mathrm{Mg}$ by milling in hydrogen (reactive milling). The milling processes and hydrogen uptake and release properties of the graphene-added $\mathrm{Mg}$ (named M5G) were investigated.

\section{EXPERIMENTAL DETAILS}

Pure Mg powder $(-20+100$ mesh, $99.8 \%$, metals basis, Alfa Aesar) and graphene (3-10 multi-layer graphene, $5-10 \mu \mathrm{m}$, purity $\geqq 99 \mathrm{wt} . \%$, thickness nanometer $3-6 \mathrm{~nm}$, surface area $150 \mathrm{~m}^{2} / \mathrm{g}$, chemical exfoliation proprietary method, Carbon Nano-material Technology Co., LTD) were used as starting materials.

Reactive milling refers to the milling of a material in a reactive gas atmosphere and in this work, the reactive milling was performed in a hydrogen atmosphere. In the present work, milling in hydrogen to obtain the final samples is referred to as reactive milling and milling in hydrogen before reactive milling to obtain the final samples is referred to as pre-milling. 
Reactive milling to prepare a M5G (6 h) sample, which has a composition of 95 wt.\% (Mg without premilling) +5 wt. $\%$ graphene, was performed in a planetary ball mill (Planetary Mono Mill; Pulverisette 6, Fritsch). Samples with the desired compositions (total weight $=8 \mathrm{~g}$ ) were mixed in a hermetically sealed stainless steel container with 105 hardened steel balls (total weight $=360 \mathrm{~g}$ ); the sample to ball weight ratio was $1 / 45$. All sample handling was performed in a glove box under $\mathrm{Ar}$ in order to prevent oxidation. The disc revolution speed was $400 \mathrm{rpm}$. The mill container (volume of $250 \mathrm{~mL}$ ) was then filled with high purity hydrogen gas ( 12 bar). Milling was performed for $6 \mathrm{~h}$, during which the mill container was refilled with hydrogen every two hours.

Pre-milling of $\mathrm{Mg}$ was performed under the conditions similar to those for the preparation of M5G $(6 \mathrm{~h})$. Premilling of $\mathrm{Mg}$ was performed for $24 \mathrm{~h}$.

To prepare M5G, which was prepared using pre-milled $\mathrm{Mg}$, the addition of graphene was also performed in a planetary ball mill (Planetary Mono Mill; Pulverisette 6, Fritsch). 95 wt.\% (Mg pre-milled for $24 \mathrm{~h})+5 \mathrm{wt} \%$ graphene (total weight $=8 \mathrm{~g}$ ) were mixed under the conditions similar to those for the preparation of $\mathrm{M} 5 \mathrm{G}$ (6 h). Reactive milling to prepare M5G was performed for $30 \mathrm{~min}$.

Table 1 shows the names, compositions, and preparation conditions of the prepared samples.

The absorbed or released hydrogen quantity was measured as a function of time in nearly constant hydrogen pressures (in 12 bar $\mathrm{H}_{2}$ for hydrogen uptake and in 1.0 bar $\mathrm{H}_{2}$ for hydrogen release) using the volumetric method, with the Sieverts' type hydrogen uptake and release apparatus described previously [13]. $0.5 \mathrm{~g}$ of the samples was used for these measurements.

Samples after reactive milling and after hydrogen uptake-release cycling were characterized by X-ray diffraction (XRD) with $\mathrm{Cu} \mathrm{K} \alpha$ radiation, using a Rigaku D/MAX 2500 powder diffractometer. The microstructures of the powders were observed using a JSM-5900 scanning electron microscope (SEM) operated at $20 \mathrm{kV}$. Raman spectrum measurements were done with an NTEGRA (NTMDT, Russia) Raman microscope with a laser excitation wavelength of $532 \mathrm{~nm}$.

Table 1. Names, compositions, and preparation conditions of the prepared samples

\begin{tabular}{|c|c|c|c|}
\hline $\begin{array}{c}\text { Sample } \\
\text { names }\end{array}$ & Compositions & $\begin{array}{c}\text { Pre-milling time } \\
\text { of } \mathrm{Mg} \text { in } \mathrm{H}_{2}, \mathrm{~h}\end{array}$ & Milling in $\mathrm{H}_{2}$ \\
\hline M5G $(6 \mathrm{~h})$ & $\begin{array}{c}95 \mathrm{wt} \% \mathrm{Mg}+5 \\
\mathrm{wt} \% \text { graphene }\end{array}$ & 0 & $6 \mathrm{~h}$ \\
\hline M5G & $\begin{array}{c}95 \mathrm{wt} \% \mathrm{Mg}+5 \\
\mathrm{wt} \% \text { graphene }\end{array}$ & 24 & $\begin{array}{c}30 \text { min with } \\
\text { graphene }\end{array}$ \\
\hline
\end{tabular}

\section{RESULTS AND DISCUSSION}

Graphene is an allotrope of carbon and consists of a single layer of carbon atoms arranged in a hexagonal lattice. Fig. 1 shows the XRD pattern of graphene, with the Miller indices of the faces marked.

The SEM micrographs of graphene at different magnifications are shown in Fig. 2. Particle sizes were not homogeneous; some particles were very large and some were fine.

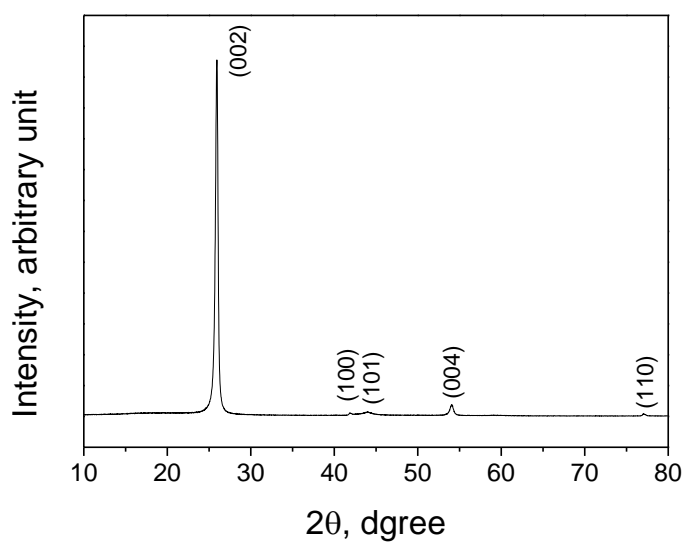

Fig. 1. XRD pattern of graphene

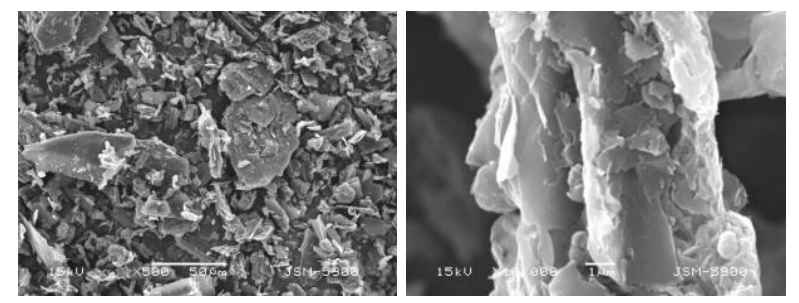

Fig. 2. SEM micrographs of graphene at different magnifications

The shapes of particles were very irregular; some particles were flat and some were rod-like. The average particle size was obtained by linear intercept technique [14]. The average particle size of the graphene was $14.1 \mu \mathrm{m}$.

Raman spectra of the graphene and as-prepared M5G are shown in Fig. 3. Raman spectrum measurements were done with a laser excitation wavelength of $532 \mathrm{~nm}$. The Raman spectrum of the graphene used in this work exhibited D, G, and 2D peaks, which can be assigned to graphene. The Raman shifts of the D, G, and 2D peaks for graphene were 1355,1584 , and $2713 \mathrm{~cm}^{-1}$, respectively. The ratio of intensities of the $D$ and $G$ peaks, $I_{D} / I_{G}$, for graphene was 0.809 . Ferrari et al. [15] reported that the shape and intensity of the 2D peak of graphene changed significantly compared with bulk graphite and the 2D peak of bulk graphite consists of two components $2 \mathrm{D}_{1}$ and $2 \mathrm{D}_{2}$. Ferrari et al. also reported that the graphene D peak is a single sharp peak, while in graphite it is a band consisting of two peaks, $D_{1}$ and $D_{2}$ [15]. The Raman spectrum in Fig. 3 a shows that the material used in this work was not graphite but graphene. It was reported that $I_{\mathrm{G}} / I_{2 \mathrm{D}}$ is about 0.3 in single-layer and increases linearly until quintuple layers, and saturated in more than sextuple layers [16]. The graphene used in this work (Fig. 2 a) had $I_{\mathrm{G}} / I_{2 \mathrm{D}}$ of 1.77 , showing that the graphene used in this work was multilayer graphene. Hodkiewicz et al [17] reported that the D peak is known as the disorder band or the defect band and the intensity of the D peak is directly proportional to the level of defects in the sample. Rusi \& S. R. Majid [18] reported that increments of $I_{\mathrm{D}} / I_{\mathrm{G}}$ can be attributed to an increase in defects on the surface of the sample that were induced during the synthesis process. The ratio of intensities of $\mathrm{D}$ and $\mathrm{G}$ peaks, $I_{\mathrm{D}} / I_{\mathrm{G}}$, for as-prepared M5G was 1.321 . The increase in $I_{\mathrm{D}} / I_{\mathrm{G}}$ after reaction-involving milling of the premilled Mg with graphene shows that defects and disordering 
in the graphene were increased. As formation of the defects in graphene, we can consider the formation of point defects (vacancies) in the lattice points of the hexagonal basal plane. For disordering, we can consider the formation of stacking fault disorder and turbostratic graphite. In the graphene, stacking fault disorder is known to be generated due to forward shearing of the hexagonal basal planes after mechanical milling [19]. The turbostratic graphite is the graphene which has curled, twisted, and rotated planes [19]. Rather than the former (the formation of defects in graphene) since high energy is considered to be required to make vacancies in the lattice points of the hexagonal basal plane, we believe that, the latter (the generation of stacking fault disorder and the formation of turbostratic graphite) occurred after milling with the pre-milled $\mathrm{Mg}$.

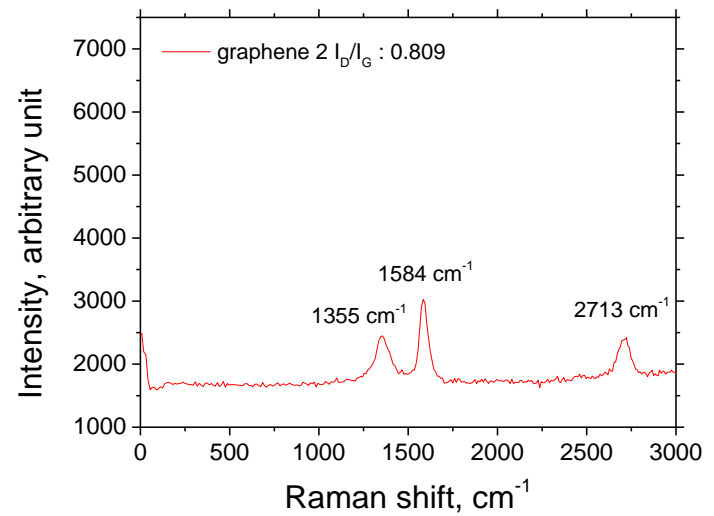

a

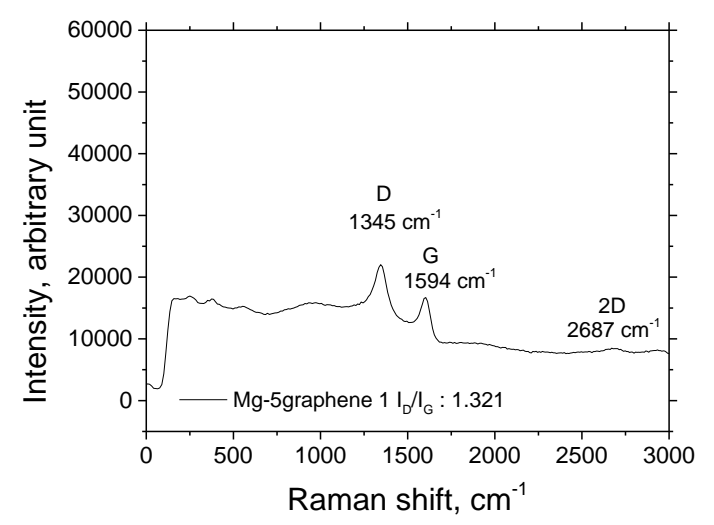

b

Fig. 3. Raman spectra: $a$ - graphene; $b$-as-prepared M5G

The quantity of hydrogen absorbed by the sample, $U$, was defined with respect to the sample weight. The quantity of hydrogen released by the sample, $R$, was also defined with respect to the sample weight. $U$ and $R$ were expressed in the unit of wt.\% hydrogen.

Fig. 4 shows the variation in the $U$ versus time $t$ curve in 12 bar $\mathrm{H}_{2}$ with the cycle number, $\mathrm{CN}$, and the $R$ versus $t$ curve in 1.0 bar $\mathrm{H}_{2}$ at $\mathrm{CN}=1$, at $593 \mathrm{~K}$ for $\mathrm{M} 5 \mathrm{G}(6 \mathrm{~h})$, which was prepared by milling a mixture of $95 \mathrm{wt} \% \mathrm{Mg}$ (not pre-milled) $+5 \mathrm{wt} . \%$ graphene for $6 \mathrm{~h}$. From $\mathrm{CN}=1$ to $\mathrm{CN}=4$, the initial hydrogen uptake rate of M5G $(6 \mathrm{~h})$ was low and the quantity of hydrogen absorbed for $60 \mathrm{~min}$, $U(60 \mathrm{~min})$, of M5G (6 h) was small. The initial hydrogen uptake rate and $U(60 \mathrm{~min})$ decreased from $\mathrm{CN}=1$ to $\mathrm{CN}=3$ and increased from $\mathrm{CN}=3$ to $\mathrm{CN}=4$. At $\mathrm{CN}=1$, M5G (6 h) absorbed $0.23 \mathrm{wt} . \%$ hydrogen for $2.5 \mathrm{~min}$,
$0.23 \mathrm{wt} \%$ hydrogen for $10 \mathrm{~min}$, and $0.37 \mathrm{wt} . \%$ hydrogen for $60 \mathrm{~min}$. At $\mathrm{CN}=4$, M5G (6 h) absorbed 0.23 wt. $\%$ hydrogen for $2.5 \mathrm{~min}, 0.23 \mathrm{wt} . \%$ hydrogen for $10 \mathrm{~min}$, and 0.27 wt. \% hydrogen for $60 \mathrm{~min}$. The $R$ versus $t$ curves were very similar from $\mathrm{CN}=1$ to $\mathrm{CN}=4$. From $\mathrm{CN}=1$ to $\mathrm{CN}=4$, the initial hydrogen release rate of M5G $(6 \mathrm{~h})$ was low and the quantity of hydrogen released for $60 \mathrm{~min}, R$ (60 min), of M5G (6 h) was small. At $\mathrm{CN}=1$, M5G (6 h) released $0.06 \mathrm{wt} \%$ hydrogen for $2.5 \mathrm{~min}, 0.09 \mathrm{wt} . \%$ hydrogen for $10 \mathrm{~min}$, and $0.13 \mathrm{wt} . \%$ hydrogen for $60 \mathrm{~min}$.

We define an effective hydrogen-storage capacity as the quantity of hydrogen absorbed for $60 \mathrm{~min}$. M5G (6 h) had a small effective hydrogen-storage capacity of 0.37 wt.\% at $593 \mathrm{~K}$ in 12 bar $\mathrm{H}_{2}$ at $\mathrm{CN}=1$.

The results in Fig. 4 show that adding graphene to $\mathrm{Mg}$ and then grinding the mixture of $\mathrm{Mg}$ and graphene in hydrogen has little effects on the improvement of the hydrogen uptake and release properties of $\mathrm{Mg}$.

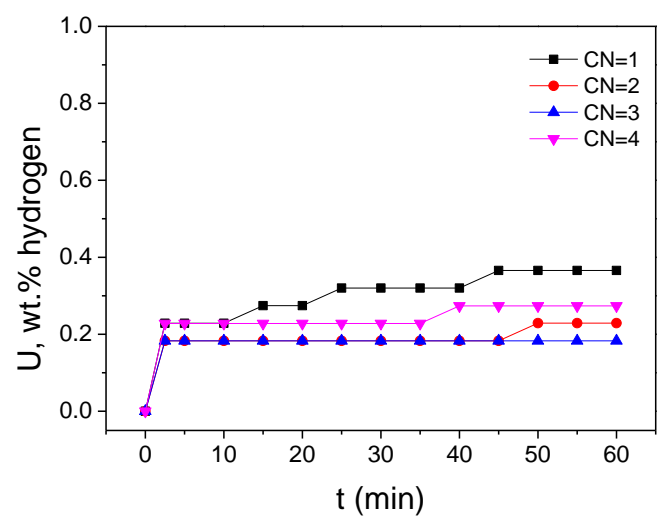

a

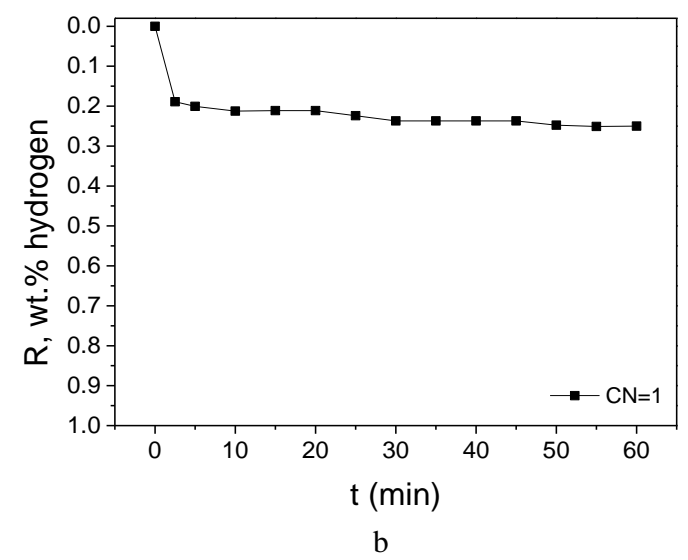

Fig. 4. a-variation in the $U$ versus $t$ curve in 12 bar $\mathrm{H}_{2}$ with the cycle number, $\mathrm{CN}$; b - the $R$ versus $t$ curve in 1.0 bar $\mathrm{H}_{2}$ at $\mathrm{CN}=1$, at $593 \mathrm{~K}$ for M5G $(6 \mathrm{~h})$

Fig. 5 shows the variation in the $U$ versus $t$ curve with the cycle number at $573 \mathrm{~K}$ in 12 bar $\mathrm{H}_{2}$ for M5G. At $\mathrm{CN}=1$, the initial hydrogen uptake rate of $\mathrm{M} 5 \mathrm{G}$ was relatively high and the quantity of hydrogen absorbed for $60 \mathrm{~min}, U(60 \mathrm{~min})$, was relatively large. As $\mathrm{CN}$ increased from one to three, the initial hydrogen uptake rate of $\mathrm{M} 5 \mathrm{G}$ increased and from $\mathrm{CN}=3$ to $\mathrm{CN}=4$, the initial hydrogen uptake rate of $\mathrm{M} 5 \mathrm{G}$ decreased. As $\mathrm{CN}$ increased from one to three, the $U$ (60 min) of $\mathrm{M} 5 \mathrm{G}$ decreased and from $\mathrm{CN}=3$ to $\mathrm{CN}=4$, the $U$ (60 min) of M5G increased. 
These results indicate that the activation of $\mathrm{M} 5 \mathrm{G}$ was completed after $\mathrm{CN}=2$. At $\mathrm{CN}=1$, M5G absorbed $0.95 \mathrm{wt} . \%$ hydrogen for $2.5 \mathrm{~min}, 2.26 \mathrm{wt} . \%$ hydrogen for $10 \mathrm{~min}$, and $5.55 \mathrm{wt} . \%$ hydrogen for $60 \mathrm{~min}$. At $\mathrm{CN}=3$, M5G absorbed $1.82 \mathrm{wt} . \%$ hydrogen for $2.5 \mathrm{~min}, 3.28 \mathrm{wt} . \%$ hydrogen for $10 \mathrm{~min}$, and $4.70 \mathrm{wt} . \%$ hydrogen for $60 \mathrm{~min}$. Table 2 presents the variations of $U$ with $t$ at $573 \mathrm{~K}$ in 12 bar $\mathrm{H}_{2}$ at $\mathrm{CN}=1-4$ for M5G.

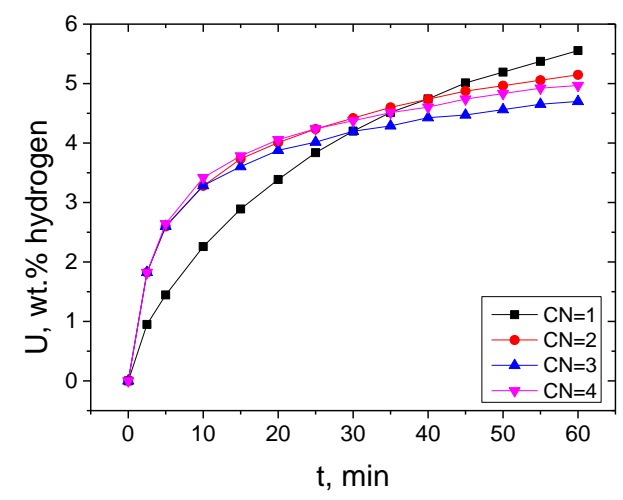

Fig. 5. Variations in the $\mathrm{U}$ versus $\mathrm{t}$ curve in 12 bar $\mathrm{H}_{2}$ with the cycle number at $573 \mathrm{~K}$ for M5G

M5G had quite a high effective hydrogen-storage capacity of 5.55 wt. $\%$ at $\mathrm{CN}=1$ and a high effective hydrogen-storage capacity of $4.70 \mathrm{wt} . \%$ at $\mathrm{CN}=3$ at $593 \mathrm{~K}$ in 12 bar $\mathrm{H}_{2}$.

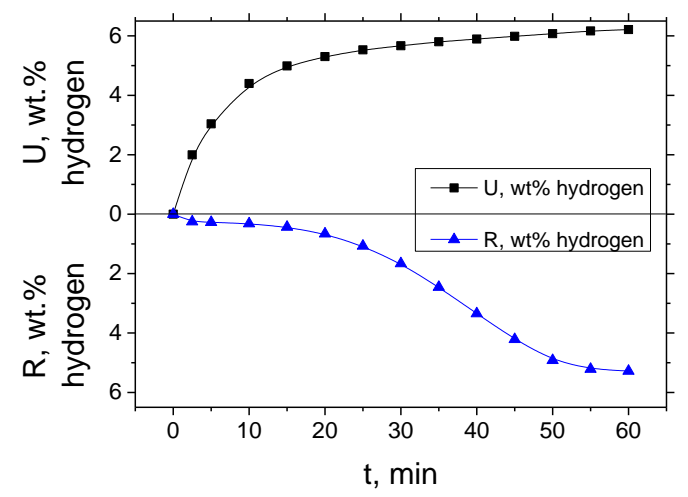

Fig. 6. $U$ versus $t$ curve in 12 bar $\mathrm{H}_{2}$ and $R$ versus $t$ curve in 1.0 bar $\mathrm{H}_{2}$ at $623 \mathrm{~K}$ at $\mathrm{CN}=3$ for M5G

The $U$ versus $t$ curve in 12 bar $\mathrm{H}_{2}$ and $R$ versus $t$ curve in 1.0 bar $\mathrm{H}_{2}$ at $623 \mathrm{~K}$ at $\mathrm{CN}=3$ for $\mathrm{M} 5 \mathrm{G}$ are shown in Fig. 6. The initial hydrogen uptake rate of M5G was quite high and the $U$ (60 min) of M5G was quite large. M5G absorbed $1.99 \mathrm{wt} \%$ hydrogen for $2.5 \mathrm{~min}, 4.40 \mathrm{wt} . \%$ hydrogen for $10 \mathrm{~min}$, and $6.21 \mathrm{wt} . \%$ hydrogen for $60 \mathrm{~min}$. The $R$ versus $t$ curve exhibited momentary hydrogen release of $0.25 \mathrm{wt} . \%$ in the beginning. This is believed to result from the hydrogen desorbed from the surfaces of the particles and released from the $\mathrm{MgH}_{2}-\mathrm{H}$ solid solution. We believe that the hydrogen quantity from the $\mathrm{MgH}_{2}-\mathrm{H}$ solid solution is smaller than that from the surfaces of the particles since it has been reported that the quantity of hydrogen contained in the $\mathrm{MgH}_{2}-\mathrm{H}$ solid solution is small [20]. The $R$ versus $t$ curve was $\mathrm{S}$-shaped, indicating that the hydrogen release reaction progressed by a nucleation and growth mechanism. The initial hydrogen release rate was relatively low, and the hydrogen release rate was the highest in about $35 \mathrm{~min}$. M5G released 0.25 wt.\% hydrogen for $2.5 \mathrm{~min}, 0.32 \mathrm{wt} . \%$ hydrogen for $10 \mathrm{~min}$, and $5.28 \mathrm{wt} \%$ hydrogen for $60 \mathrm{~min}$. Table 3 shows the variations of $R$ with $t$ in 1.0 bar $\mathrm{H}_{2}$ and $U$ with $t$ in 12 bar $\mathrm{H}_{2}$ at $623 \mathrm{~K}$ at $\mathrm{CN}=3$ for M5G.

Table 2. Variations of $U$ (wt.\% hydrogen) with $t$ at $573 \mathrm{~K}$ in 12 bar $\mathrm{H}_{2}$ at $\mathrm{CN}=1-4$ for M5G

\begin{tabular}{|l|c|c|c|c|c|}
\hline & $2.5 \mathrm{~min}$ & $5 \mathrm{~min}$ & $10 \mathrm{~min}$ & $30 \mathrm{~min}$ & $60 \mathrm{~min}$ \\
\hline $\mathrm{CN}=1$ & 0.95 & 1.44 & 2.26 & 4.20 & 5.55 \\
\hline $\mathrm{CN}=2$ & 1.82 & 2.60 & 3.28 & 4.42 & 5.15 \\
\hline $\mathrm{CN}=3$ & 1.82 & 2.60 & 3.28 & 4.20 & 4.70 \\
\hline $\mathrm{CN}=4$ & 1.82 & 2.64 & 3.42 & 4.38 & 4.97 \\
\hline
\end{tabular}

Table 3. Variations of $R$ (wt.\% hydrogen) with $\mathrm{t}$ in $1.0 \mathrm{bar}_{2}$ and $U$ with $t$ in 12 bar $\mathrm{H}_{2}$ at $623 \mathrm{~K}$ at $\mathrm{CN}=3$ for $\mathrm{M} 5 \mathrm{G}$

\begin{tabular}{|c|c|c|c|c|c|}
\hline & $2.5 \mathrm{~min}$ & $5 \mathrm{~min}$ & $10 \mathrm{~min}$ & $30 \mathrm{~min}$ & $60 \mathrm{~min}$ \\
\hline$U$ & 1.99 & 3.04 & 4.40 & 5.67 & 6.21 \\
\hline$R$ & 0.25 & 0.27 & 0.32 & 1.66 & 5.28 \\
\hline
\end{tabular}

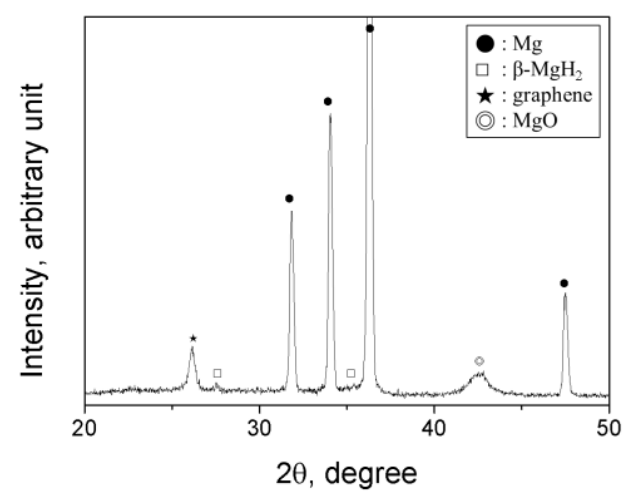

Fig. 7. XRD pattern of M5G dehydrogenated at the $4^{\text {th }}$ hydrogen uptake-release cycle

Fig. 7 shows the XRD pattern of M5G dehydrogenated at the $4^{\text {th }}$ hydrogen absorption-release cycle. The M5G after reactive milling contained a large amount of $\mathrm{Mg}$ and small amounts of $\beta-\mathrm{MgH}_{2}$ and graphene. This shows that $\beta-\mathrm{MgH}_{2}$ formed by the reaction of $\mathrm{Mg}$ with $\mathrm{H}_{2}$ during milling in hydrogen. $\beta-\mathrm{MgH}_{2}$ is a low pressure form of magnesium hydride with a tetragonal structure. The M5G dehydrogenated at the $4^{\text {th }}$ hydrogen uptake-release cycle contained a large amount of $\mathrm{Mg}$, a small amount of graphene, and very small amounts of $\beta-\mathrm{MgH}_{2}$ and $\mathrm{MgO}$. A very small amount of $\mathrm{MgO}$ is considered to be formed by the reaction of $\mathrm{Mg}$ with oxygen adsorbed on the particle surfaces during treating the samples to obtain the XRD pattern. The grain sizes of $\mathrm{Mg}$ and $\mathrm{MgH}_{2}$ in the samples were calculated using Scherrer formula. The grain sizes of $\mathrm{Mg}$ and $\mathrm{MgH}_{2}$ in the $\mathrm{M} 5 \mathrm{G}$ after reactive milling were $25.8 \mathrm{~nm}$ and $17.9 \mathrm{~nm}$, respectively. The grain sizes of $\mathrm{Mg}$ and $\mathrm{MgH}_{2}$ in the $\mathrm{M} 5 \mathrm{G}$ dehydrogenated at the $4^{\text {th }}$ hydrogen uptake-release cycle were $30.9 \mathrm{~nm}$ and $56.9 \mathrm{~nm}$, respectively. The grain size of $\mathrm{Mg}$ increased after hydrogen uptake-release cycling.

The SEM micrographs of M5G after reactive milling and M5G dehydrogenated at the $4^{\text {th }}$ hydrogen uptakerelease cycle is shown in Fig. 8. M5G after reactive milling had no homogeneous particle size and its particles had 
some cracks and the particle surfaces were undulated. M5G dehydrogenated at the $4^{\text {th }}$ hydrogen uptake-release cycle had a microstructure similar to that of M5G after reactive grinding. The average particle size of the M5G after reactive milling was $11.7 \mu \mathrm{m}$ while that of the M5G dehydrogenated at the $4^{\text {th }}$ hydrogen uptake-release cycle was $12.50 \mu \mathrm{m}$, indicating that these two samples had similar particle sizes. However, the particles of M5G dehydrogenated at the $4^{\text {th }}$ hydrogen uptake-release cycle had more cracks than those of M5G after reactive milling. The particles of $\mathrm{M} 5 \mathrm{G}$ dehydrogenated at the $4^{\text {th }}$ hydrogen uptake-release cycle had some fine particles on their surfaces. The formation of cracks and fine particles with hydrogen uptake-release cycling are considered to result from the expansion and contraction of $\mathrm{Mg}$ with hydrogen uptake-release cycling.
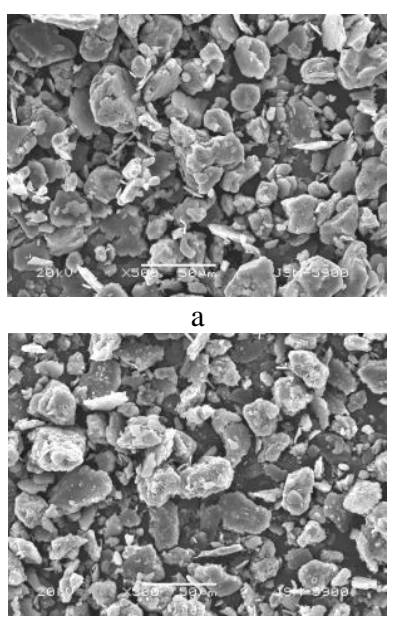

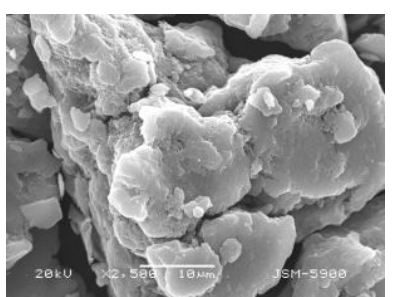

b

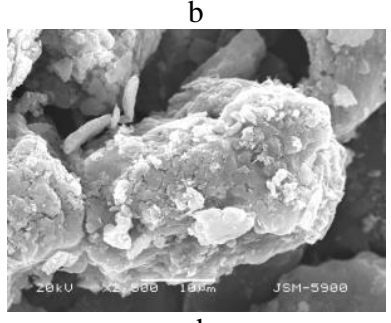

Fig. 8. SEM micrographs of M5G: $a, b$-after reactive milling; c, d-dehydrogenated at the $4^{\text {th }}$ hydrogen uptake-release cycle

Fig. 5 shows that from $\mathrm{CN}=1$ to $\mathrm{CN}=3$, the initial hydrogen uptake rate of M5G increased and the $U(60 \mathrm{~min})$ of $\mathrm{M} 5 \mathrm{G}$ decreased. It is believed that from $\mathrm{CN}=1$ to $\mathrm{CN}=3$, the initial hydrogen uptake rate of M5G increased due to formation cracks on the surfaces of particles from expansion and contraction of the particles and the $U$ (60 min) of M5G decreased due to coalescence of cracks inside particles.

M5G (6 h), which was prepared by reactive milling without pre-milling $\mathrm{Mg}$, has a low initial hydrogen uptake rate and a small $U(60 \mathrm{~min})$. It is considered that acting of the added graphene as a lubricant hindered the pulverization of $\mathrm{Mg}$. To pulverize $\mathrm{Mg}$ particles, they were milled in hydrogen for relatively long times $(24 \mathrm{~h})$. Premilling of $\mathrm{Mg}$ and then adding graphene by milling in hydrogen significantly increased the initial hydrogen uptake rate and the $\mathrm{U}$ (60 $\mathrm{min}$ ) of $\mathrm{Mg}$.

Pre-milling of $\mathrm{Mg}$ is believed to create defects (leading to facilitation of nucleation), produce cracks and clean surfaces (leading to increase in reactivity), and decrease particle sizes (leading to diminution of diffusion distances or increasing the flux of the diffusing hydrogen atoms). Adding graphene, which has a large specific surface area, to the pre-milled $\mathrm{Mg}$ is believed to decrease particle sizes by graphene's filling the cracks of $\mathrm{Mg}$ particles and helping the $\mathrm{Mg}$ particles be separated [21-24].
The hydrogen uptake-release cycling is also believed to create defects, produce cracks and clean surfaces, and decrease particle sizes due to expansion (by hydrogen uptake) and contraction (by hydrogen release) of $\mathrm{Mg}$ [25-28].

\section{CONCLUSIONS}

Adding graphene to $\mathrm{Mg}$ and then milling the mixture of $\mathrm{Mg}$ and graphene in hydrogen for $6 \mathrm{~h}$ (named M5G $(6 \mathrm{~h})$ ) had little effects on the improvement of hydrogen uptake and release properties of $\mathrm{Mg}$. Pre-milling of $\mathrm{Mg}$ (for $24 \mathrm{~h}$ ) and then adding graphene by milling in hydrogen (for $30 \mathrm{~min}$ ) (named M5G) significantly increased the hydrogen uptake and release rates and the quantities of hydrogen absorbed and released for $60 \mathrm{~min}$ of $\mathrm{Mg}$. The activation of M5G was completed after cycle number, $\mathrm{CN}$, of two $(\mathrm{CN}=2)$. M5G had a high effective hydrogen-storage capacity of $6.21 \mathrm{wt} . \%$ at $623 \mathrm{~K}$ in $12 \mathrm{bar}$ $\mathrm{H}_{2}$ at $\mathrm{CN}=3$. $\mathrm{M} 5 \mathrm{G}$ released 0.25 wt. $\%$ hydrogen for $2.5 \mathrm{~min}$ and $5.28 \mathrm{wt} . \%$ hydrogen for $60 \mathrm{~min} \mathrm{H}_{2}$ in $1.0 \mathrm{bar}$ $\mathrm{H}_{2}$ at $623 \mathrm{~K}$ at $\mathrm{CN}=3$. Pre-milling of $\mathrm{Mg}$ and then adding graphene and are believed to create defects, produce cracks and clean surfaces, and decrease particle sizes. The hydrogen uptake-release cycling is believed to bring about similar effects.

\section{Acknowledgements}

This research was supported by Basic Science Research Program through the National Research Foundation of Korea (NRF) funded by the Ministry of Education (grant number NRF-2017R1D1A1B03030515).

\section{REFERENCES}

1. Krozer, A., Kasemo, B. Equilibrium Hydrogen Uptake and Associated Kinetics for the $\mathrm{Mg}-\mathrm{H}_{2}$ System at Low Pressures Journal of Physics: Condensed Matter 1(8) 1989: pp. $1533-1538$.

https://doi.org/10.1088/0953-8984/1/8/017

2. Karty, A., Genossar, J.G., Rudman, P.S. Hydriding and Dehydriding Kinetics of $\mathrm{Mg}$ in a $\mathrm{Mg} / \mathrm{Mg}_{2} \mathrm{Cu}$ Eutectic Alloy: Pressure Sweep Method Journal of Applied Physics 50 (11) 1979: pp. $7200-7209$.

https://doi.org/10.1063/1.325832

3. Bobet, J.L. Akiba, E., Nakamura, Y., Darriet, B. Study of $\mathrm{Mg}-\mathrm{M}(\mathrm{M}=\mathrm{Co}, \mathrm{Ni}$ and $\mathrm{Fe}$ ) Mixture Elaborated by Reactive Mechanical Alloying-Hydrogen Sorption Properties International Journal of Hydrogen Energy 25 (10) 2000: pp. $987-996$. https://doi.org/10.1016/S0360-3199(00)00002-1

4. Reilly, J.J., Wiswall, R.H. Reaction of Hydrogen with Alloys of Magnesium and Copper Inorganic Chemistry 7 (11) 1968: pp. 2254-2256. https://doi.org/10.1021/ic50069a016

5. Calizzi, M., Chericoni, D., Jepsen, L.H., Jensen, T.R., Pasquini, L. Mg-Ti Nanoparticles with Superior Kinetics for Hydrogen Storage International Journal of Hydrogen Energy 41 (32) 2016: pp. $14447-14454$. https://doi.org/10.1016/j.ijhydene.2016.03.071

6. Tran, N.E., Imam, M.A., Feng, C.R. Evaluation of Hydrogen Storage Characteristics of Magnesium-Misch 
Metal Alloys Journal of Alloys Compounds $359(1-2)$ 2003: pp. $225-229$.

https://doi.org/10.1016/S0925-8388(03)00176-2

7. Huot, J., Tremblay, M.L., Schulz, R. Synthesis of Nanocrystalline Hydrogen Storage Materials Journal of Alloys Compounds 356-357 2003: pp. 603-607. https://doi.org/10.1016/S0925-8388(03)00120-8

8. Popilevsky, L., Skripnyuk, V.M., Beregovsky, M., Senzen, M., Amouyal, Y., Rabkin, E. Hydrogen Storage and Thermal Transport Properties of Pelletized Porous Mg2 wt.\% Multiwall Carbon Nanotubes and Mg-2 wt.\% Graphite Composites International Journal of Hydrogen Energy 41 (32) 2016: pp. $14461-14474$.

https://doi.org/10.1016/j.ijhydene.2016.03.014

9. Guoxian, L., Erde, W., Shoushi, F. Hydrogen Absorption and Desorption Characteristics of Mechanically Milled Mg35 wt.\% FeTi1.2 Powders Journal of Alloys Compounds 223 (1) 1995: pp. $111-114$. https://doi.org/10.1016/0925-8388(94)01465-5

10. Liang, G., Boily, S., Huot, J., Neste, A.V., Schulz, R. Hydrogen Absorption Properties of a Mechanically Milled $\mathrm{Mg}-50$ wt.\% LaNis Composite Journal of Alloys Compounds $268(1-2)$ 1998: pp. 302-307. https://doi.org/10.1016/S0925-8388(97)00607-5

11. Khrussanova, M., Bobet, J.L., $\quad$ Terzieva, M., Chevalier, B., Radev, D., Peshev, P., Darriet, B. Hydrogen Storage Characteristics of Magnesium Mechanically Alloyed with $\mathrm{YNi}_{5}-\mathrm{xAlx}(\mathrm{x}=0,1$ and 3$)$ Intermetallics Journal of Alloys Compounds $307(1-2)$ 2000: pp. 283-289. https://doi.org/10.1016/S0925-8388(00)00842-2

12. Imamura, H., Kusuhara, M., Minami, S., Matsumoto, M., Masanari, K., Sakata, Y., Itoh, K., Fukunaga, T. Carbon Nanocomposites Synthesized by High-Energy Mechanical Milling of Graphite and Magnesium for Hydrogen Storage Acta Materialia 51 (20) 2003: pp. $6407-6414$.

https://doi.org/10.1016/j.actamat.2003.08.010

13. Song, M.Y., Baek, S.H., Bobet, J.L., Song, J., Hong, S.H. Hydrogen Storage Properties of a Mg-Ni-Fe Mixture Prepared via Planetary Ball Milling in a $\mathrm{H}_{2}$ Atmosphere International Journal of Hydrogen Energy 35 (19) 2010: pp. 10366-10372. https://doi.org/10.1016/j.ijhydene.2010.07.161

14. Kingery, W.D., Bowen, H.K., Uhlmann, D.R. Introduction to Ceramics, $2^{\text {nd }}$ edition, A Wiley-Interscience Publication, John Wiley \& Sons New York, 1976: p. 728. https://trove.nla.gov.au/version/45656624

15. Ferrari, A.C., Meyer, J.C., Scardaci, V., Casiraghi, C., Lazzeri, M., $\quad$ Mauri, F., $\quad$ Piscanec, S., Jiang, D., Novoselov, K.S., Roth, S., Geim, A.K. Raman Spectrum of Graphene and Graphene Layers Physical Review Letters 97 2006: pp. 187401.

https://doi.org/10.1103/PhysRevLett.97.187401

16. https://www.nanophoton.net/applications/22.html

17. https://tools.thermofisher.com/content/sfs/brochures/D19505 $\sim$.pdf
18. Rusi., Majid, S.R. Green Synthesis of In Situ Electrodeposited $\mathrm{rGO} / \mathrm{MnO}_{2}$ Nanocomposite for High Energy Density Supercapacitors Scientific Reports 5 2015: Article number: 16195. https://doi.org/10.1038/srep16195

19. Varin, R.A., Czujko, T., Wronski, Z.S. Nanomaterials for Solid State Hydrogen Storage, Springer, 2009: pp. 301-302. https://doi.org/10.1007/978-0-387-77712-2

20. Stampfer, J.F.Jr., Holley, C.E.Jr., Suttle, J.F. The MagnesiumHydrogen System American Chemical Society $82(14)$ 1959: pp. 3504-3508. https://doi.org/10.1021/ja01499a006

21. Park, H.R., Kwak, Y.J., Song, M.Y. Increase in the Hydrogen-Sorption Rates and Hydrogen-Storage Capacity of $\mathrm{MgH}_{2}$ by Adding a Small Proportion of $\mathrm{Zn}\left(\mathrm{BH}_{4}\right)_{2}$ Korean Journal of Metals and Materials 55 (9) 2017: pp. 656-662. https://doi.org/10.3365/KJMM.2017.55.9.657

22. Hong, S.H., Kwak, Y.J., Song, M.Y. Enhancement of the Hydrogen-Storage Characteristics of $\mathrm{Mg}$ by Adding $\mathrm{Mg}_{2} \mathrm{Ni}$ and $\mathrm{Ni}$ to $\mathrm{MgH}_{2}$ via High Energy Ball Milling in Hydrogen Atmosphere Korean Journal of Metals and materials 56 (1) 2018: pp. 59-65. https://doi.org/10.3365/KJMM.2018.56.1.59

23. Hong, S.H., Song, M.Y. Hydrogen Absorption and Release Properties of $\mathrm{MgH}_{2}, \mathrm{Mg}_{2} \mathrm{Ni}$, and $\mathrm{Ni}$-added $\mathrm{Mg}$ via Reactive Mechanical Grinding Korean Journal of Metals and Materials 56 (2) 2018: pp. 155-162. https://doi.org/10.3365/KJMM.2018.56.2.155

24. Song, M.Y., Kwak, Y.J. Comparison of the Hydrogen Release Properties of $\mathrm{Zn}\left(\mathrm{BH}_{4}\right)_{2}$-Added $\mathrm{MgH}_{2}$ Alloy and $\mathrm{Zn}\left(\mathrm{BH}_{4}\right)_{2}$ and $\mathrm{Ni}$-added $\mathrm{MgH}_{2}$ Alloy Korean Journal of Metals and Materials 56 (3) 2018: pp. 244-251. https://doi.org/10.3365/KJMM.2018.56.3.244

25. Kwak, Y.J., Park, H.R., Song, M.Y. Advancement in the Hydrogen Absorbing and Releasing Kinetics of $\mathrm{MgH}_{2}$ by Mixing with Small Percentages of $\mathrm{Zn}\left(\mathrm{BH}_{4}\right)_{2}$ and $\mathrm{Ni}$ Metals and Materials International 22 (2) 2018: pp. 423-432. https://doi.org/10.1007/s12540-018-0036-4

26. Song, M.Y., Choi, E., Kwak, Y.J. Development of a MgBased Alloy with a Hydrogen-Storage Capacity of $7 \mathrm{wt} \%$ by Adding a Polymer CMC via Transformation-Involving Milling Korean Journal of Metals and Materials $56(5)$ 2018: pp. $392-399$. https://doi.org/10.3365/KJMM.2018.56.5.392

27. Song, M.Y., Kwak, Y.J. Hydrogen uptake and release characteristics of $\mathrm{Mg}-\mathrm{xTaF}_{5}-\mathrm{xVCl}_{3}(\mathrm{x}=1.25,2.5$, and 5) Korean Journal of Metals and Materials $56(8)$ 2018: pp. $611-619$. https://doi.org/10.3365/KJMM.2018.56.8.611

28. Song, M.Y., Choi, E., Kwak, Y.J. Raising the Dehydrogenation Rate of a Mg-CMC (Carboxymethylcellulose, Sodium Salt) Composite by Alloying Ni via Hydride-Forming Milling Korean Journal of Metals and Materials 56 (8) 2018: pp. 620-627. https://doi.org/10.3365/KJMM.2018.56.8.620 